\title{
PENGARUH BIOAKTIVATOR DARI FERMENTASI KULIT PISANG DAN AIR CUCIAN BERAS TERHADAP WAKTU MATANG KOMPOS
}

\author{
Nurudin Achmad Fauzi ${ }^{1}$, Nur Hilal ${ }^{1}$, Yulianto ${ }^{1)}$ \\ ${ }^{1)}$ Poltekkes Kemenkes Semarang
}

\begin{abstract}
Abstrak
Sampah organik merupakan jenis sampah yang dapat memicu keberadaan vektor pembawa agent penyakit. Salah satu cara untuk mengatasi masalah sampah organik adalah dengan pembuatan kompos. Waktu matang kompos dapat dipersingkat dengan penambahan bioaktivator. Bioaktivator dapat dibuat dari bahan-bahan organik yang di fermentasikan. Bahan organik yang dapat digunakan antara lain kulit pisang dan air cucian beras. Hal tersebut karena kandungan gizi yang terkandung dalam kulit pisang dan air cucian beras dapat memicu pertumbuhan mikroba pengurai. Adapun tujuan penelitian ini untuk memanfaakan limbah kulit pisang sebagai bahan dasar bioaktivator yang difermentasi bersama cucian beras.

Penelitian ini merupakan penelitian quasi experiment dengan desain time series. Objek yang diteliti adalah waktu matang kompos dengan bioaktivator $0 \mathrm{ml}, 10 \mathrm{ml}$ dan $30 \mathrm{ml}$. Data diambil dengan cara melakukan pengukuran suhu kompos dengan pengulangan sebanyak tiga kali.

Hasil penilitian dengan analisis anova menunjukkan nilai signifikan $0,017<0,05$ sehingga ada perbedaan secara signifikan anatara ketiga variasi. Uji lanjut menunjukan perbedaan signifikan ada pada bioaktivator $0 \mathrm{ml}$ dengan $30 \mathrm{ml}$. Berdsarkasn uji t-test yang dilakukan antara bioaktivator $0 \mathrm{ml}$ dengan $10 \mathrm{ml}, 10 \mathrm{ml}$ dengan $30 \mathrm{ml}$ dan $0 \mathrm{ml}$ dengan $30 \mathrm{ml}$ didapatkan nilai signifikan $0,065>0,05 ; 0,275>$ 0,05 dan $0,008<0,005$, arinya tidak terdapat perbedaan signifikan antara bioaktivator $0 \mathrm{ml}$ dengan 10 $\mathrm{ml}$ dan $10 \mathrm{ml}$ dengan $30 \mathrm{ml}$.

Berdasarkan hasil analisis penelitian disimpullkan bahwa penambahan bioaktivator $30 \mathrm{ml}$ berpengaruh terhadap waktu matang kompos dan penambahan bioaktivator $10 \mathrm{ml}$ tidak terlalu berpengaruh terhadap waktu matang kompos.
\end{abstract}

Kata Kunci: Kulit Pisang, Bioaktivator, Kompos

\begin{abstract}
[The Effect Of Bioactivator From Banana Peel And Rice Washing Fermentation On Compost Ripe Time] Organic waste is a type of waste that can triger the existence of a disease-carryng vector. One way to overcome the problem of organic waste is by making compost. Compost cooking time can be shortened by adding bioactivator. Bioactivators can be made from fermented organic materials. Organic materials that can be used include banana peels and rice washing water. That is because the nutrional content contained in banana peels and rice washing water can be trigger the growth of decomposing microbes. The purpose of this study is to use banana peel waste as a basic ingredient of bioactivator fermented with rice washing.

This research is a quasi experimental research with time series design. The object under study was the time to compost with $0 \mathrm{ml}, 10 \mathrm{ml}$ and $30 \mathrm{ml}$ bioactivator. Data is taken by measuring the compost temperature by repeating three times.

The result of the study anova analysis showed a significant value of 0,017<0,05, so there are significant differences between the three variations. While further test were carried out between $0 \mathrm{ml}$ and $30 \mathrm{ml}$ bioactivators. From the t-test carried out between bioactivators $0 \mathrm{ml}$ with $10 \mathrm{ml}, 10 \mathrm{ml}$ with $30 \mathrm{ml}$ and $0 \mathrm{ml}$ with $30 \mathrm{ml}$, obtained a significant value 0,065 > 0,05; 0,275 >0,05 dan 0,008 <0,005. So there is no significant diference between bioactivators $0 \mathrm{vml}$ with $10 \mathrm{ml}$ and $10 \mathrm{ml}$ with $30 \mathrm{ml}$.

Based on the result of the study, it was concluded that the addition of $30 \mathrm{ml}$ bioactivator had an effect on the compost maturity time and the addition of $10 \mathrm{ml}$ bioactivator did not significantly affect the time of compost maturity.
\end{abstract}

Keywords: Banana Peel, Bioactivator, compost 


\section{Pendahuluan}

Berdasarkan Peraturan Menteri Dalam Negeri No. 33 Tahun 2010 tentang Pedoman Pengelolaan Sampah, sampah adalah sisa kegiata sehari-hari manusia dan atau proses alam yang berbentuk padat. Keberadaan sampah dapat menjadi masalah penting yang perlu ditangani dan jika dibiarkan menumpuk tanpa adanya pengolahan, maka akan menyebabkan penularan penyakit. Untuk menangani permasalahan penumpukan sampah secara liar perlu dilakukan pengurangan sampah seperti pendaur ulangan sampah.

Kegiatan pendaur ulangan sampah dalam rangka menjadikan sampah sebagai sumberdaya, berkaitan erat dengan komposisi sampah di Indonesia yang sekitar $71 \%$ merupakan sampah yang dapat dijadikan kompos (Kementrian Negara Lingkungan Hidup 2008. Statistik Persampahan Negara 2008).

Kompos adalah bahan-bahan organik atausampah organik yang telah mengalami proses pelapukan, karena adanya interaksi antar mikroorganisme pembusuk yang bekerja (L. Murbandono, 2007). Salah satu proses pembuatan kompos adalah dengan penambahan bioaktivator dalam upaya pengomposan (Hery Suryoko, 2011).

Bioaktivator adalah bahan aktif biologi dengan kandungan mikroorganisme yang digunakan untuk meningkatkan aktivitas proses komposting dan secara aktif mampu membantu mendekomposisi sampah (Wahyono, 2010 dalam Aminah Sarwa, 2014). Mikroorganisme yang dimaksud adalah bakteri pembusuk seperti Pseudomonas sp. dan Bacillus sp.

Kulit pisang mengandung bakteri Pseudomonas sp. (Novak, 2003) dan Bacillus sp. (Moiedi dik., 2013). Bakteri yang bekerja membutuhkan asupan Karbohidrat sebagai sumber energi (Trubus, 2012).Karbohidrat bisa didapatkan dari air cucian beras sehingga air cucian beras dapat memicu tumbuhnya bakteri pembusuk (Dalimartha, 2008).

\section{Bahan dan Metode}

Jenis penilitian yang digunakan dalam penilitian ini adalah penelitian Quasi Experimental dengan desain Time series. Dalam penilitan ini terdaoat 3 perlakuan yaitu kompos dengan bioaktivator $0 \mathrm{ml}, 10 \mathrm{ml}$ dan $30 \mathrm{ml}$ dengan pengulangan masing-masing perlakuan sebanyak 3 kali.

Pembuatan kompos dilakukan pada kotak tempat pengomposan dengan atap karung. Volume awal kompos adalah 270 liter dengan bahan sampah organik yang sudah dicacah dengan mesin cacah.

Selama penilitian dilakukan pengadukan tiap 4 hari sekali dan pengamatan suhu, kelembaban, $\mathrm{pH}$ serta volume setiap hari selama 30 hari. Indikator yang digunakan untuk mengetahui waktu matang kompos adalah suhu yang stabil selama 3 hari.

Bioaktivator dibuat dengan cara memfermentasikan kulit pisang sebanyak $5 \mathrm{~kg}$ dan air cucian beras 5 liter pada ember yang ditutup koran selama 15 hari, dengan penambahan gula merah $1 \mathrm{~kg}$ sebagai sumber makanan bagi bakteri (Nurul Puspita Palupi, 2015).

Analisis yang dipakai adalah analisis t-test untuk dua kelompok independen dan One Way Anova untuk 3 kelompok independen.

\section{Hasil dan Pembahasan}

a. Suhu

Gambar 4.2 Grafik Perubahan Suhu

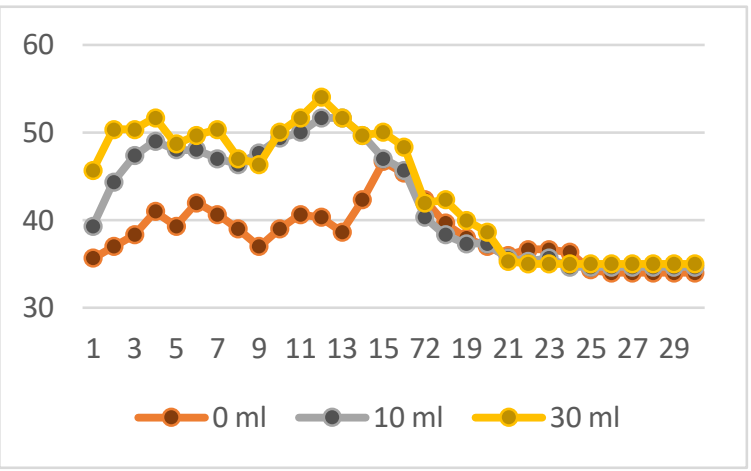

Hasil pengukuran suhu pada kompos dengan pemberian bioaktivator $0 \mathrm{ml}$ sebesar $38,33^{\circ} \mathrm{C}$ dengan suhu puncak $46,7^{\circ} \mathrm{C}$ lebih kecil dibanding rata-rata suhu kompos dengan pemberian $10 \mathrm{ml}\left(42,15^{\circ} \mathrm{C}\right)$ dengan suhu puncak $51,7^{\circ} \mathrm{C}$ dan rata-rata suhu kompos dengan pemberian bioaktivator $30 \mathrm{ml}$ $\left(43,62^{\circ} \mathrm{C}\right)$ dengan suhu puncak $54^{\circ} \mathrm{C}$.

Semakin tinggi aktifitas mikroba maka semakin tingggi suhu, serta semakin cepat proses dekomposisi dan aktifitas pengomposan akan cepat pada suhu yang berkisar antara $30-70^{\circ} \mathrm{C}$ (Isroi dan Nuheti, 2009)..

Karena semakin tinggi aktifitas mikroba semakin tinggi suhu, maka aktifitas mikroba tertinggi ada pada suhu puncak tertinggi dan kompos dengan rata-rata aktifitas mikroba tertinggi ada pada kompos dengan rata-rata suhu tertinggi yaitu kompos dengan penambahan bioaktvator $30 \mathrm{ml}$ yang memiliki suhu puncak tertinggi dan rata-rata suhu tertinggi. 
b. $\mathrm{pH}$

Gambar 4.3. Grafik Perubahan $\mathrm{pH}$

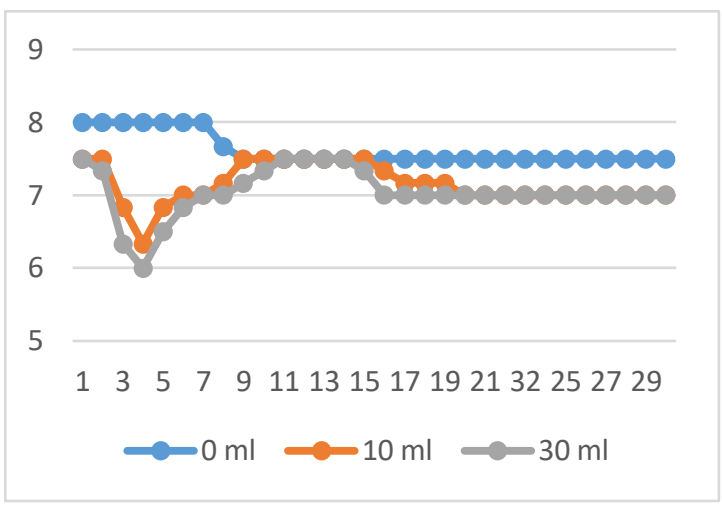

Rata-rata pengukuran $\mathrm{pH}$ tertinggi ada pada kompos dengan pemberian bioaktivator $0 \mathrm{ml}$ yaitu sebesar 7,6 sedangkan untuk rata-rata $\mathrm{pH}$ terendah sebesar 7 yaitu pada kompos dengan pemberian bioaktivator $30 \mathrm{ml}$.

Proses pengomposan dapat terjadi pada kisaran $\mathrm{pH}$ yang lebar dan $\mathrm{pH}$ optimum pada proses pengomposan berkisar antara 6,5 - 7,5 (Isroi dan Nurheti Yuliarti, 2009), sehingga rata-rata $\mathrm{pH}$ kompos dengan penambahan bioaktivator $10 \mathrm{ml}$ dan $30 \mathrm{ml}$ berada pada tingkat $\mathrm{pH}$ optimum untuk proses pengomposan dan kompos dengan penambahan bioaktivator $0 \mathrm{ml}$ memiliki rata-rata $\mathrm{pH}$ yang tidak baik.

\section{c. Kelembaban}

Gambar 4.4. Grafik Perubahan Kelembaban

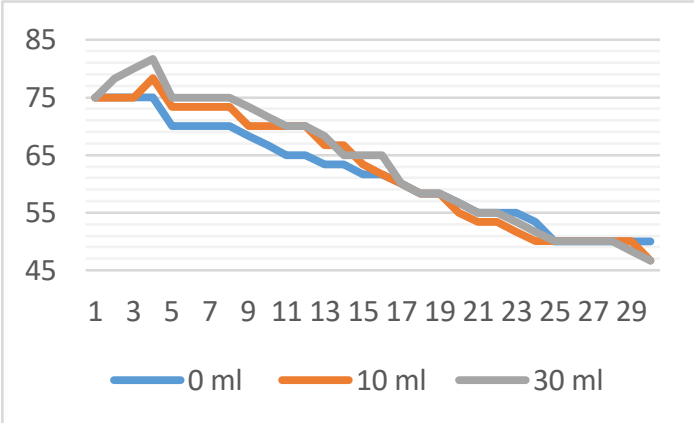

Rata-rata kelembaban kompos tertinggi yaitu kompos dengan pemberian bioaktivator $30 \mathrm{ml}$ sebesar 63,56\%, dan terendah adalah kompos dengan pemberian bioaktivator $0 \mathrm{ml}$ yaitu sebesar $61,56 \%$.

Mikroorganisme dapat memanfaatkan bahan organik apabila bahan organik tersebut larut dalam air dan kelembaban optimum pengomposan adalah sekitar 40\%-60\% (Isroi dan Nurheti Yuliarti, 2009), sehingga rata-rata kelembaban kompos pada penambahan bioaktivator $0 \mathrm{ml}, 10 \mathrm{ml}$ dan $30 \mathrm{ml}$ tidak berada pada kelembaban optimum sedangkan kelembaban optimum terjadi mulai hari ke-17, karena pada hari ke-17 kelembaban kompos berkurang mencapai nilai $60 \%$. d. Volume

Gambar 4.5. Grafik Perubahan Volume

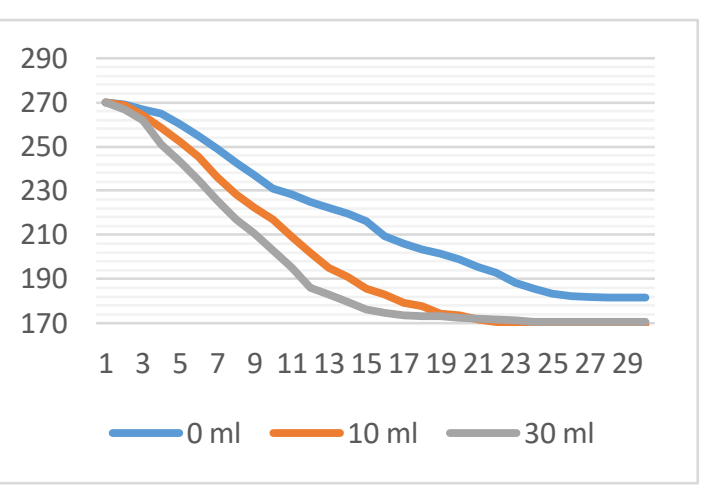

Volume akhir kompos dengan penambahan bioaktivator $0 \mathrm{ml}, 10 \mathrm{ml}$ dan $30 \mathrm{ml}$ adalah 182 liter, 170 liter, dan 171 liter. Penyusutan volume terjadi selama proses pematangan kompos, saat kompos matang penyusutan yang terjadi berkisar antara 2040\% (Heri Soeryoko, 2011).

Kompos dengan penambahan bioaktivator 0 $\mathrm{ml}, 10 \mathrm{ml}$ dan $30 \mathrm{ml}$ secara berurutan telah mengalami penyusutan volume rata-rata sebesar $32,7 \%, 37,1 \%$ dan $36,8 \%$, sehingga kompos dengan penambahan bioaktivator $0 \mathrm{ml}, 10 \mathrm{ml}$ dan $30 \mathrm{ml}$ sudah memenuhi salah satu ciri kompos yang sudah matang karena penyusutan volume berkisar antara $20-40 \%$.

\section{e. Waktu Matang Kompos}

Tabel 4.1. Hasil Pemantauan waktu matang kompos

\begin{tabular}{|l|l|l|l|l|}
\hline \multirow{2}{*}{ No. } & \multirow{2}{*}{ Bioaktivator } & \multicolumn{3}{|c|}{ Waktu Matang / hari } \\
\cline { 3 - 5 } & & R1 & R2 & R3 \\
\hline 1 & $0 \mathrm{ml}$ & 27 & 26 & 28 \\
\hline 2 & $10 \mathrm{ml}$ & 26 & 23 & 24 \\
\hline 3 & $20 \mathrm{ml}$ & 22 & 23 & 24 \\
\hline
\end{tabular}

Rata-rata keseluruhan waktu matang kompos adalah 24,7 hari, dimana waktu rata-rata tercepat ada pada kompos dengan pemberian bioaktivator $30 \mathrm{ml}$ yaitu 23 hari sedangkan waktu rata-rata terlambat ada pada kompos dengan pemberian biaktivator $0 \mathrm{ml}$ yaitu 27 hari.

Waktu matang kompos didapatkan dari hari dimana suhu kompos mulai stabil selama 3 hari (Isroi dan Nurheti, 2009). Selain ditandai stabilnya suhu, kompos yang matang juga mengalami penyusutan volume antara 20-40\% (Heri Soeryoko, 2011), sehingga waktu matang kompos pada kompos dengan penambahan bioaktivator $0 \mathrm{ml}$ secara berurutan adalah 27 hari, 26 hari dan 28 hari.

\section{f. Analisis Univariat}

Anaslisis bivariat dilakukan dengan uji $\mathrm{T}$ test. hasil uji T-test menunjukan bahwa perbedaan waktu matang kompos setelah pemberian bioaktivator $0 \mathrm{ml}$ dan bioaktivator $10 \mathrm{ml}$ memiliki 
hasil kesimpulan yang sama dengan perbedaan waktu matang kompos setelah pemberian bioaktivator $10 \mathrm{ml}$ dan bioaktivator $30 \mathrm{ml}$, yaitu tidak adanya perbedaan yang signifikan karena nilai sig.(2-tailed) > 0,05. Perbedaan yang signifikan terjadi pada perbedaan waktu matang kompos dengan penambahan bioaktivator $0 \mathrm{ml}$ dan $30 \mathrm{ml}$ karena didapatkan nilai signifikasi $<0,05$.

\section{g. Analisis Bivariat}

Analsis multivariat dalam penilitian ini menggunakan uji anova. Dari hasil uji anova yang di lakukan didapatkan kesimpulan bahwa penambahan bioaktivator $30 \mathrm{ml}$ berpengaruh terhadap waktu matang kompos dan penambahan bioaktivator $10 \mathrm{ml}$ tidak terlalu berpengaruh terhadap waktu matang kompos.

\section{Kesimpulan}

a. Waktu matang kompos setelah penambahan bioaktivator dari fermentasi kulit pisang dan air cucian beras sebanyak $10 \mathrm{ml}$ dan $30 \mathrm{ml}$ liter secara berurutan adalah 24,3 hari dan 23 hari dengan waktu matang tercepat pada penambahan bioaktivator $30 \mathrm{ml}$ liter.

b. Waktu matang kompos tanpa penambahan bioaktivator dari fermentasi kulit pisang dan air cucian beras adalah 26 hari. c. Suhu terbaik adalah kompos dengan penambahan bioaktivator $30 \mathrm{ml}$ yang mengalami suhu puncak tertinggi yaitu sebesar $54^{\circ} \mathrm{C}$.

d. pH yang baik adalah pada kompos dengan penambahan bioaktivator $10 \mathrm{ml}$ dan $30 \mathrm{ml}$ yaitu 7,15 dan 7,04 yang merupakan $\mathrm{pH}$ ratarata pada tingkat $\mathrm{pH}$ optimum pengomposan.

e. Kelembaban kompos dengan penambahan bioaktivator $0 \mathrm{ml}, 10 \mathrm{ml}$ dan $30 \mathrm{ml}$ memiliki nilai kelembaban rata-rata dibawah tingkat kelembaban optimum yang menyebabkan pengomposan lambat.

f. Volume pada kompos dengan penambahan bioaktivator $0 \mathrm{ml}, 10 \mathrm{ml}$ dan $30 \mathrm{ml}$ sudah baik karena mengalami penyusutan antara $20-40 \%$, yaitu sebesar 32,7\%, 37,1\% dan 36,8\%.

g. Dari anisilis yang dilakukan diperoleh hasil bahwa waktu matang kompos dengan penambahan bioaktivator dari fermentasi kulit pisang dan cucian beras sebanyak $30 \mathrm{ml}$ berpengaruh terhadap waktu matang kompos.

h. Dari anisilis yang dilakukan diperoleh hasil bahwa waktu matang kompos dengan penambahan bioaktivator dari fermentasi kulit pisang dan cucian beras sebanyak $10 \mathrm{ml}$ tidak terlalu berpengaruh terhadap waktu matang kompos.

\section{Daftar Pustaka}

Aminah Sarwa Endah, 2014. "Pengajuan Beberapa Metofe Pembuatan Bioaktivator Guna Peningkatan Kualitas Pupuk Organik Cair". Purwokerto : UMP

Dalimartha S., 2008. Atlas Tumbuhan Obat Indonesia. Jakarta : Trubus Agriwidya

Hery Soeryoko, 2011. Kiat Pintar Memproduksi Kompos Pengurai Buatan Sendiri, Yogyakarta : Lily Publisher

Isroi dan Nurheti, 2009. Kompos cara mudah murah , dan cepat menghasilkan kompos. Yogyakarta : C.V ANDI OFFSET

Kementrian lingkungan hidup, 2008. Statistik persampahan Indonesia Tahun 2008

L. Murbandono,2007. Membuat Kompos. Jakarta : Penebar Swadaya

Novak F.R., 2003, "Banana peel : a possible source of infection in the treatment of nipple fissures". Rio De Janeiro : Instituto Fernandes Figueira, Rio de Janeiro, RJ, 22250-020, Brasil
Nurul Puspita Palupi, 2015. Karakteristik Kimia Pupuk Cair Asal Limbah Kulit Pisang Kepok dan Pengaruhnya Terhadap Tinggi Tanaman Kedelai. Samarinda : Universitas Mulawarwan.

Nurheti Yuliarti,2009,1001 Cara Menghasilkan Pupuk Organik. Yogyakarta : Lily Publisher

Moiedi Sunira Paul dan V.Judia Harriet Sumathy, 2013. "Production of -amylase from banana peels with Bacillus subtilis using solid state fermentation". Chennai : Postgraduate \& Research Department of Biotechnology, Women s Christian College, Chennai, India

Peraturan Menteri Dalam Negri no 33 Tahun 2010 Tentang Pedoman Pengelolaan Sampah

Tri Cahyono. 2018. Panduan Penulisan Tugas Akhir. Purwokerto. Politeknik Kesehatan Kemenkes Semarang Jurusan Kesehatan Lingkungan Purwokerto

Trubus Redaksi, 2012. Mikroba Juru Masak Tanaman Dongkrak Hasil Panen 3 Kali Lipat. Jakarta : Trubus 